\title{
Monitoring system of an energy efficient school building.
}

\author{
Iosif Boros ${ }^{1, *}$, Dan Stoian ${ }^{1}$, Tamás Nagy-György ${ }^{1}$ and Valeriu Stoian ${ }^{1}$ \\ 1"Politehnica" University of Timisoara, Faculty of Civil Engineering, Civil Engineering and Services \\ Department, 2 Traian Lalescu Street, Timisoara, Romania
}

\begin{abstract}
The paper presents details regarding the implemented monitoring system of heat loss, interior comfort and energy consumption particularities of an energy efficient school building in Romania. Despite the fact that there is an emphasis on energy saving and sustainability in the building industry legislation and policies, there are still too few examples of good practice at local level. Recent trends have brought changes in how designers solve specific details like thermal insulation thicknesses and use of renewable energy but further improvement is required for a more detailed understanding of the entire building's energy balance behaviour both on overall and specific details level. Therefore, a complex monitoring system was built in a carefully designed and constructed school building in order to collect relevant real-time data of every specific part of the thermal envelope, the HVAC systems and interior comfort parameters. The main purpose of the system is to highlight the order of magnitude of the differences between the design and the real-time values of the most significant parameters, the importance of each detail and also the need of further research development in this field.
\end{abstract}

\section{Introduction}

In order to combat the effects of greenhouse gas emissions, a series of legislative measures covering all areas of activity have been imposed to all European Union members.

Given that the construction industry is one of these areas, the principles of recent legislation [1] include measures such as : use of renewable energy, the rehabilitation of existing buildings, global cost analysis, implementation of energy efficient buildings, use of local energy sources and materials with reduced environmental footprint and use of the primary energy term.

Although these measures are appropriate, solid improvement is still required in certain subdomains like: expertise of designers, constructors and supervisors, quality control, consumption metering, examples of good practice, thematic visits, global costs concept implementation and correlation of legislation with practice.

Monitoring systems [2] and real-time analysis of construction behavior can provide reliable data for a more detailed energy balance understanding and to convince investors of the benefits of energy efficiency solutions.

\footnotetext{
* Corresponding author: iosif.boros@ student.upt.ro
} 


\subsection{Case study description}

The construction in question (Fig. 1. and Fig. 2.) is a four storey high school building with an area of $4000 \mathrm{~m}^{2}$, which is located in Salonta, Romania. The main functions of the building are: 11 classrooms, 4 laboratories, administration, reading room, library, 200 seat capacity canteen, 400 meals / day capacity kitchen and a 60 bed capacity dormitory.

Site limitations have imposed a simple and compact form of classic architectural style as it had to be integrated into the existing built environment. The thermal agent for heating, cooling and domestic hot water is prepared in an independent mechanical room.

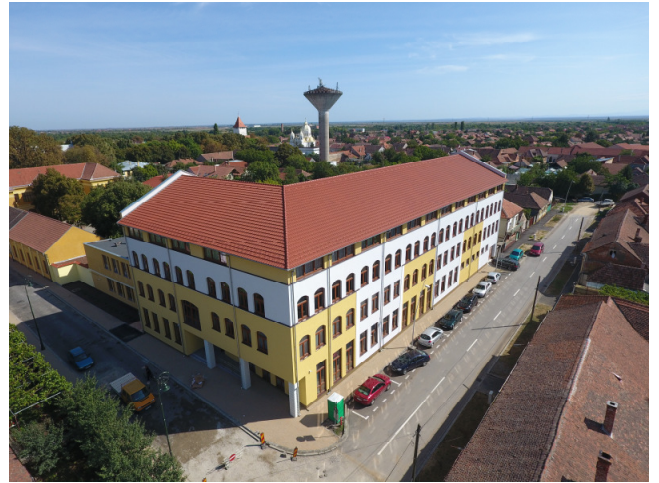

Fig. 1. Overview

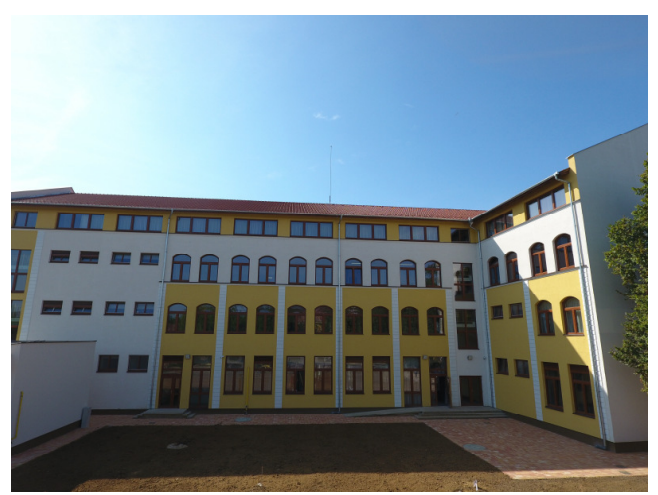

Fig. 2. School building

\subsection{Design}

In the beginning of the design process, a global cost analysis was carried out in order to highlight the energy consumption and cost differences between the traditional and energy efficient solutions [3]. This analysis was used by the decision factors to adopt the most suitable requirements in the design theme. The difference between the initial costs of the two building options is approximately $10 \%$ and the economy generated by the low consumption in the energy efficient version is recovered in 6 years (Fig. 3.).

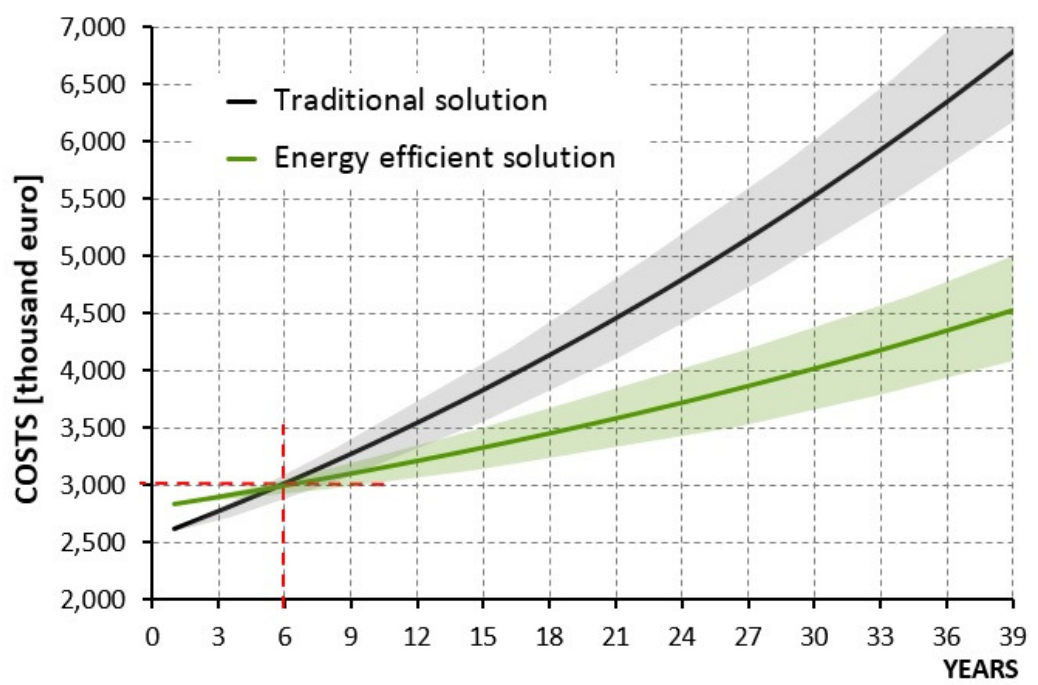

Fig. 3. Global cost analyis 
During the design phase, the Passive House Planning Package (PHPP) [4] and the precise climatic data for the studied site [5] were used to determine the energy balance of the building.

Regarding the implementation of passive house principles, the following specific measures have been adopted: compact form, high transmittance of envelope elements (Fig. 4. and Fig. 5.), use internal and solar gains in the thermal balance calculation, thermal bridge free design (Fig. 6. and Fig. 7.), use of renewable energy and envelope air tightness. Furthermore, specific aspects like large number of occupants during normal operation periods and high glazing ratio involve significant heat gains and danger of overheating.

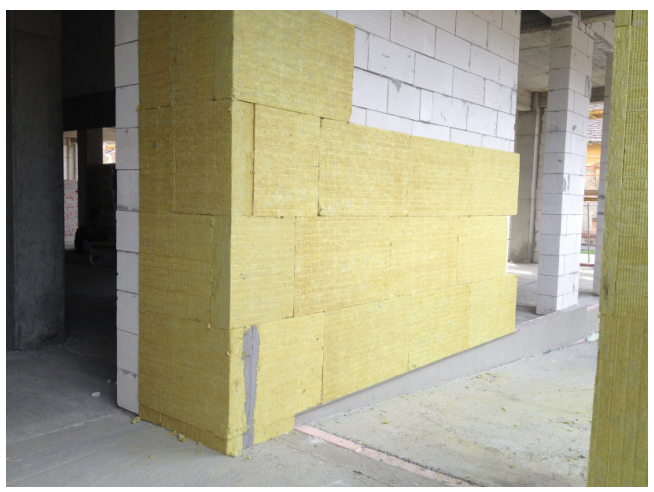

Fig. 4. Thermal insulation of exterior walls

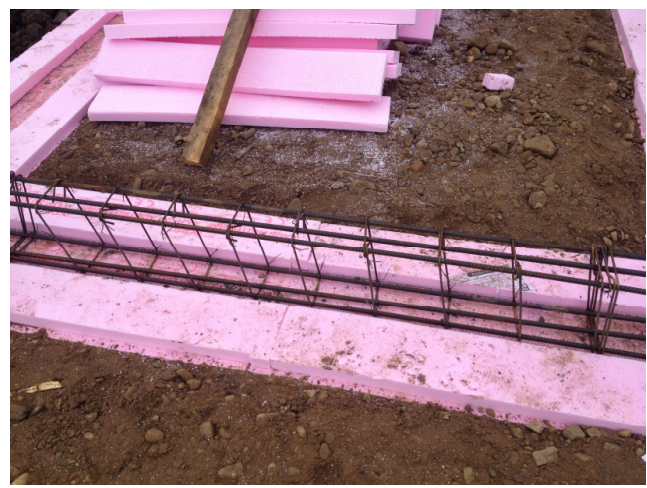

Fig. 6. Thermal bridge free design of beams

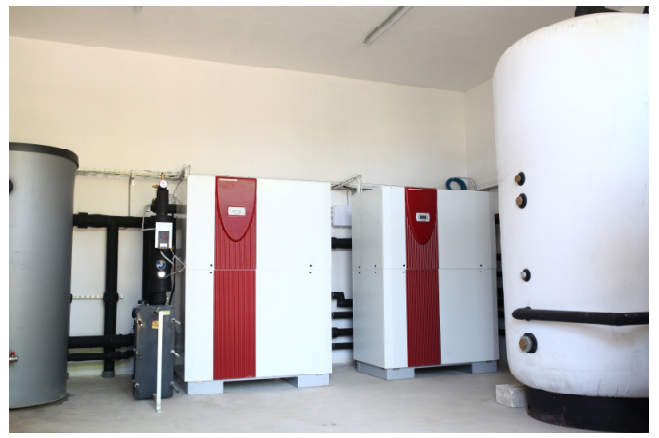

Fig. 8. Mechanical room heat pumps and boiler

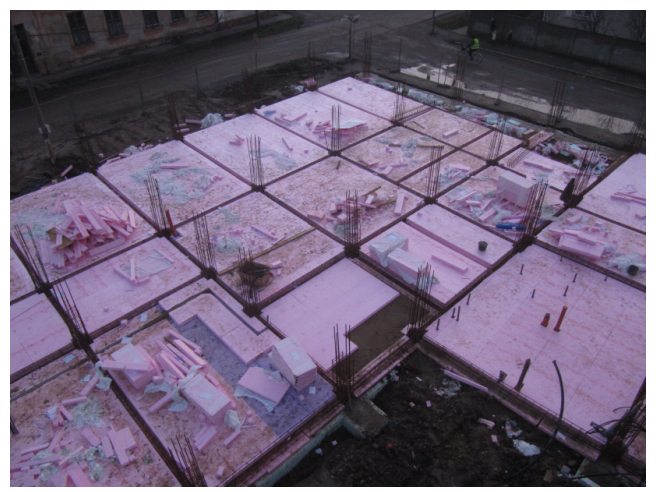

Fig. 5. Thermal insulation of ground slab

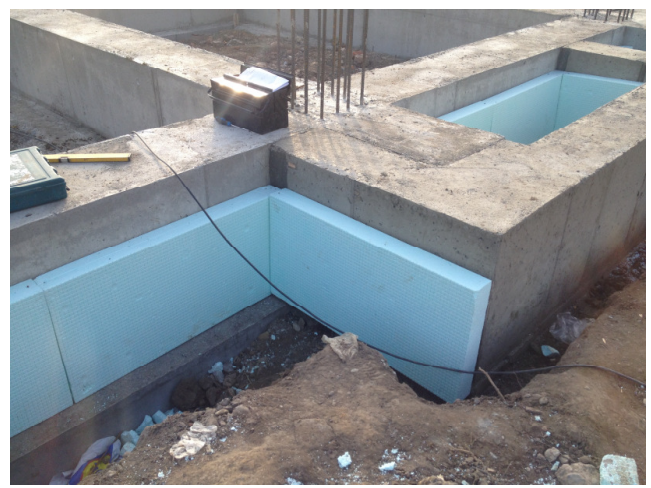

Fig. 7. Thermal bridge free design of foundations

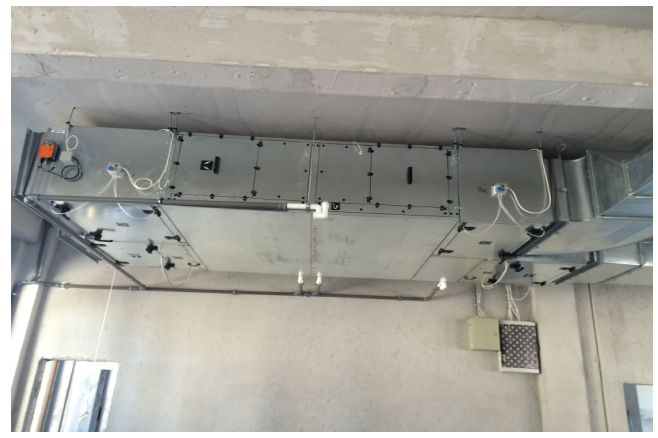

Fig. 9. Mechanical ventilation unit 
The thermal agent for heating, cooling and domestic hot water is perpared with a soil-water and a water-water heat pump which are connected to 14 drills of 120 depth each (Fig. 8.). The thermal distribution system consists of floor and ceiling fan-coils which are operated by digital thermostats in each room. In order to ensure the domestic hot water requirements, a 3000 liter boiler with $10 \mathrm{~cm}$ thick insulation layer has been provided (Fig. 8.).

A $75 \%$ efficiency heat recovery mechanical system has been implemented to assure the fresh air intake without window opening. The system is independent for each level and destination and is supplied with $\mathrm{CO}_{2}$ sensors to adjust its functioning (Fig. 9.).

\section{Monitoring system}

A complex monitoring system [6] was installed in the building to demonstrate the advantages of the energy efficient solutions and to provide an instrument of control of the interior comfort parameters.

The system consists of 660 measuring elements which are made up of temperature, humidity, $\mathrm{CO}_{2}$, flow meters and electric energy consumption meters. All the elements are connected to multiple data acquisition stations which store the real-time data [7].

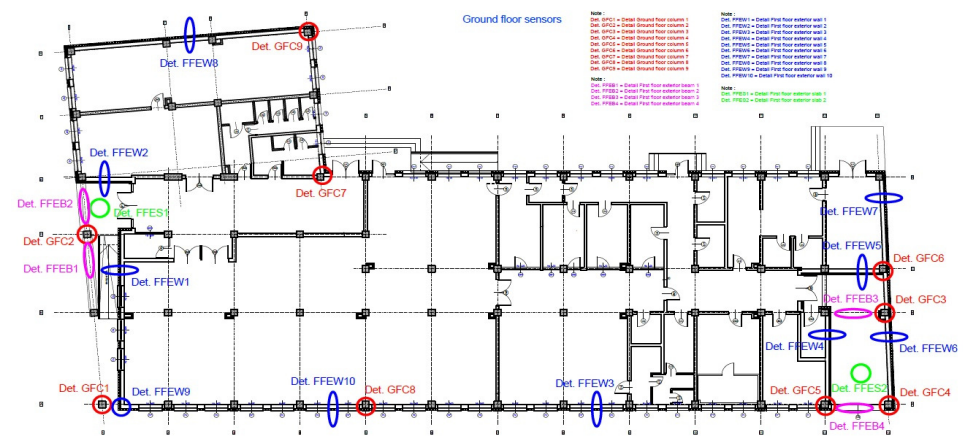

Fig. 10. Monitoring system plan

\subsection{Building envelope}

Temperature sensors have been installed in all relevant envelope elements and thermal bridge zones to compare measurements with the numerical modelling and to highlight the obtained differences. These sensors have been set in foundations, ground floor, exterior beams (Fig. 11.), walls (Fig. 12.) and columns, attic slab and walls.

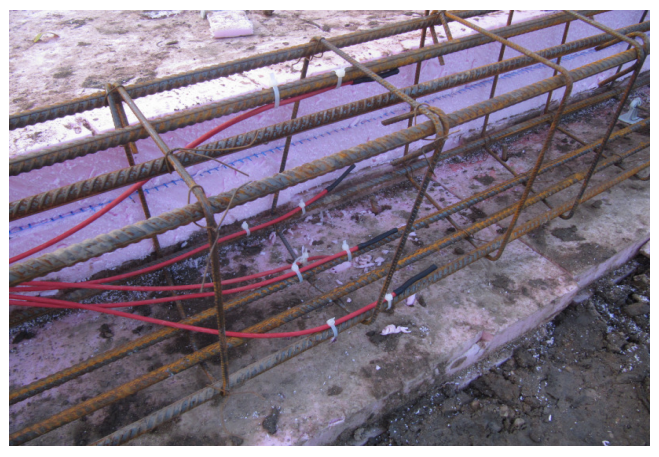

Fig. 11. Ground floor exterior beam sensors

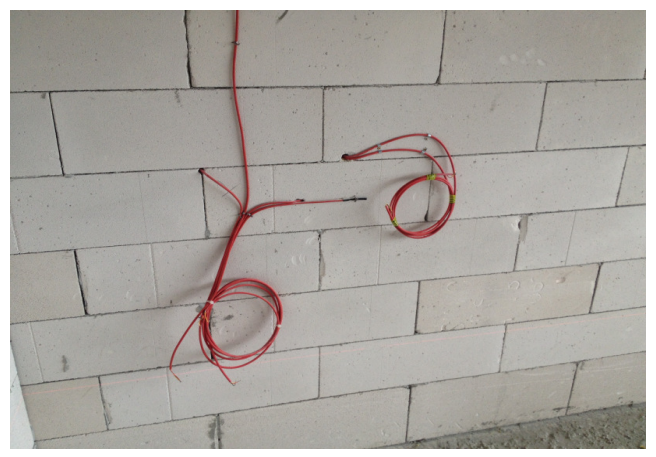

Fig. 12. Exterior wall sensors 


\subsection{HVAC systems}

Temperature sensors (Fig. 13., Fig. 14. and Fig. 16.) and flow meters (Fig. 15.) are installed in all significant positions on the entire thermal, ventilation and domestic hot water systems, both in the mechanical room and in the building to provide complete data regarding their efficiency, distribution losses but also detailed information about their behavior throughout the entire route from source to destination.
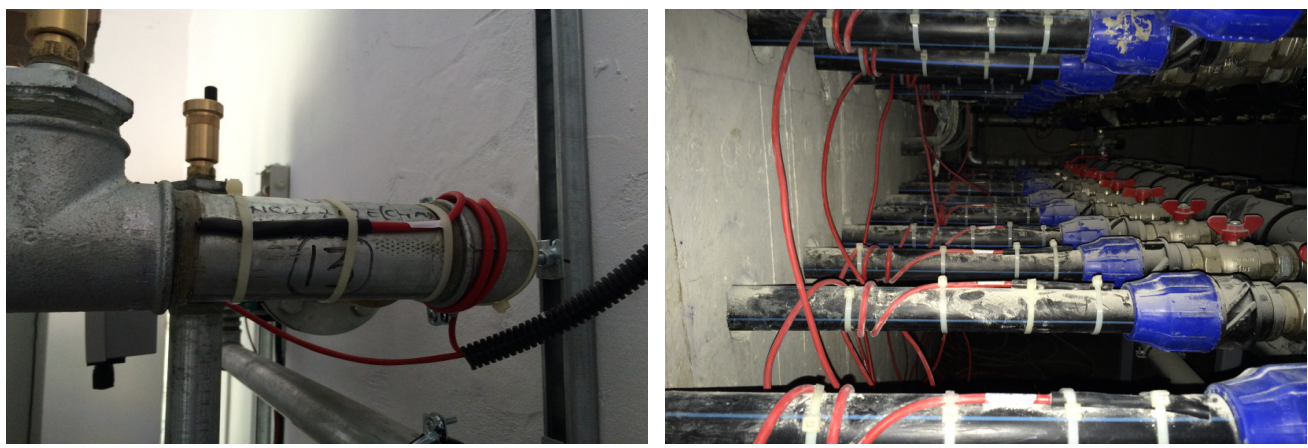

Fig. 13. Mechanical room sensors

Fig. 14. Heat pump drills sensors
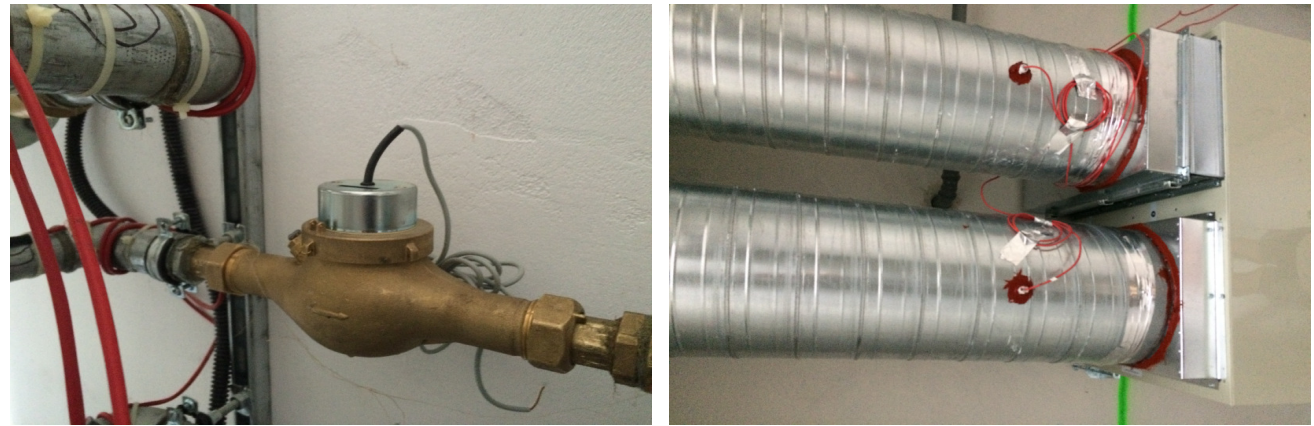

Fig. 15. Mechanical room flow meters

Fig. 16. Ventilation sensors

\subsection{Energy consumption and interior comfort}

An energy consumption meter has been set up on every level and an additional two in the kitchen area and the mechanical room. The meters placement configuration was chosen to break down the consumption for each main function.

The interior comfort parameters are measured by temperature, humidity and $\mathrm{CO}_{2}$ sensors which are installed at $1.50 \mathrm{~m}$ height in every type of room.

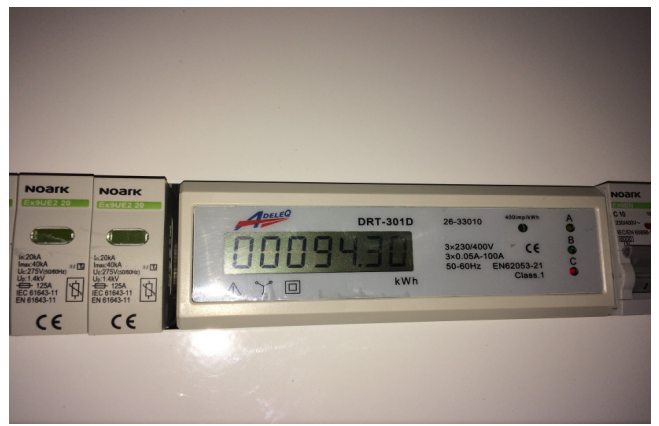

Fig. 17. Electric consumption meters

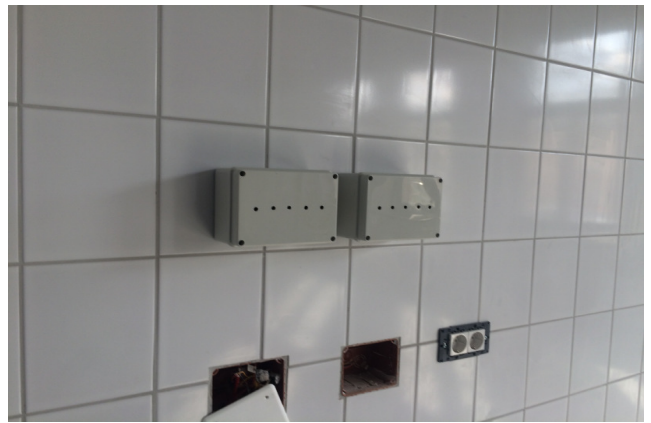

Fig. 18. Interior comfort sensors 


\section{Conclusions}

Until now, the school building has been used for nine months at a capacity of $75 \%$ because the kitchen and the dormitory have not yet been fully equipped.

The measured average energy consumption is $1.10 \mathrm{kWh} / \mathrm{m}^{2} /$ month for heating in comparison to the design value of $1.16 \mathrm{kWh} / \mathrm{m}^{2} /$ month. Regarding the total energy consumption of the building, the measured value is $1.80 \mathrm{kWh} / \mathrm{m}^{2} /$ month in comparison to the design value of $3.20 \mathrm{kWh} / \mathrm{m}^{2} /$ month. Although the usage is not yet at full capacity, the differences between the two types of values can be explained by inconsistent and unprecise numerical methodology, construction quality control imperfections and differences between user behavior patterns. After the completion of the entire year of functioning at full capacity, the measured data will be most relevant.

Reduced energy consumption and higher indoor comfort are obvious advantages of energy efficient buildings and can represent the necessary motivation for investors to adopt these systems. Monitoring systems can offer reliable data which can be used to improve the existing methodology and the way designers, investors and users regard their buildings.

Research in the field of energy efficiency of buildings is essential for the evolution of the construction industry but can also be a tool to highlight environmental issues and to promote awareness.

\section{References}

1. European Union, Dir. 2002/91/CE of The European Parliament and of the Council of 16 December 2002 on the Energy Performance of Buildings (2002)

2. D. Stoian, V. Stoian, D. Dan, Instal. pt. constr. conf. amb., 22, 355-360 (2013)

3. A.J. Marszal, P. Heiselberg, Energy, 36-9, 5600-5609 (2011)

4. Passive House Institute, Passive House Planning Package 2007 - Specifications for Quality Approved Passive Houses (2007)

5. http://www.meteonorm.com/

6. I. Boros, T. Nagy-György, C. Floruț, D. Dan, Intern. Conf. on Innov. Res. (2015)

7. I. Boros, K. Schmiedt, C. Tănasă, T. Nagy-György, D. Dan, V. Stoian, Intern. J. of Ener. and Envir., 10, 243-247 (2016) 